\title{
ONTWIKKELING VAN HET ADMINISTRATIEBEGRIP
}

\author{
door Prof. R. W. Starreveld
}

Onder de titel „Wat is administratie” werd in het februarinummer een beschouwing gegeven over de definiëring van het begrip ,administratie”. Daarin werd o.m. gesteld, dat de afgrenzing van dit begrip een kwestie van doelmatigheid is en dat de grenzen zich daardoor bij verandering der organisatorische verhoudingen, economische omstandigheden of technische mogelijkheden verplaatsen. Ook de voortgezette bezinning op de problematiek waarmede de administratie geconfronteerd wordt, heeft uiteraard de grenzen geleidelijk doen verschuiven.

Het kan bevorderlijk zijn voor het inzicht in de samenhang tussen de verschillende onderdelen van de administratie die in de loop der jaren aan de oorspronkelijke kern zijn toegevoegd, wanneer wij de ontwikkeling welke de administratie in het bijzonder gedurende de laatste eeuwen heeft doorgemaakt in dit artikel eens in het kort de revue laten passeren. Wij zullen ons daarbij beperken tot dat deel van de administratie dat in het vorige artikel werd aangeduid als behorende tot sector $\mathrm{A}$.

Wanneer wij ons tot het geven van een dergelijk overzicht zetten, realiseren wij ons dat de ontwikkelingsgang van de administratie niet in alle landen dezelfde is geweest en dat ook het desbetreffende ontwikkelingsproces van bedrijf tot bedrijf duidelijke verschillen vertoont. Niet alleen de volgorde van de ontwikkelingsfasen is verschillend, doch ook de huidige stand van de ontwikkeling loopt vrij sterk uiteen, zodat de administratie in tal van bedrijven in een stadium verkeert, dat andere bedrijven reeds lang achter de rug hebben. Een zekere stylering van de ontwikkelingsgeschiedenis is daarom onvermijdelijk.

Onder dit voorbehoud kunnen t.a.v. de ontwikkeling van sector A de volgende 12 fasen worden onderscheiden. Met name de laatste vijf zijn nog betrekkelijk jong. Sommige daarvan zijn nog allerminst in ruime kring als ontwikkelingsfasen van de administratie onderkend.

\section{Registratie van geldmiddelen, vorderingen en schulden}

De grote aanwendbaarheid, begeerlijkheid en verplaatsbaarheid van geld en het immateriële karakter van vorderingen en schulden hebben reeds in de verre oudheid behoefte aan registratie doen ontstaan. De daarbij toegepaste systematiek kon uiterst eenvoudig zijn. Incidenteel vond daarnaast ook de registratie van voorraden plaats. De geldmiddelen en de afzonderlijke vorderingen en schulden konden zonder bezwaar zonder enige systematische samenhang los van elkaar geregistreerd worden. Ook de incidenteel voorkomende voorraadregistraties stonden normaliter los van de overige administratie.

\section{Uitbreiding tot dubbel boekhouden}

Men begint oog te krijgen voor de systematische samenhang tussen de mutaties in de verschillende categorieën van bezittingen en schulden (kapitaal- en vermogensbestanddelen). De registratie gaat zich daardoor uitbreiden tot

- de goederen en andere activa, voorzover niet reeds begrepen onder 1.

- het eigen vermogen (het saldo van bezittingen en schulden)

- de verlies- en winstcomponenten (c.q. lasten en baten).

Daardoor kan een zekere geslotenheid van het gehele registratiesysteem worden 
verkregen, gebaseerd op de gelijkheid van de som der bezittingen enerzijds en de som van schulden en ,zuiver vermogen" anderzijds. Aanvankelijk blijft daarbij de toepassing van de evenwichtsgedachte beperkt tot een registratie van de uit commerciële transacties voortvloeiende mutaties in de geldmiddelen, vorderingen en schulden enerzijds en de daarbij ontvangen dan wel afgegeven tegenwaarden anderzijds. Men stelt zich daarbij de volgende vragen:

- waarvoor werden de ontstane schulden aangegaan en waarvoor werden de uitgegeven gelden besteed? (ontvangen tegenwaarden c.q. schulddelging)

- waarvoor werden de ontstane vorderingen en de ontvangen gelden verkregen? (afgegeven tegenwaarden c.q. afgewikkelde vorderingen)

Door in aansluiting daarop op de een of andere wijze de kosten van de afgegeven tegenwaarden alsmede de z.g. transitorische posten vast te stellen, kan aan de hand van de aldus verkregen gegevens zowel het perioderesultaat worden berekend als een balans worden opgesteld. (De op zichzelf niet onbelangrijke ontwikkeling van hierop aansluitende methoden om de resultaatbepaling en de balansopstelling te vereenvoudigen en te versnellen, zoals de verschillende methoden ter verkrijging van een ,permanence de l'inventaire", kunnen in het kader van de onderhavige schets gevoeglijk buiten beschouwing blijven).

\section{Uitbouw van de tegenwaarderegistratie ten beboeve van de kwantitatieve voorraadbeheersing}

Zowel ten behoeve van de controle op de voorraadbewaarders als ter verkrijging van een basis voor beslissingen m.b.t. de aanvaarding van orders, de herbevoorrading, het opruimen van voorraden e.d., wordt de tegenwaarderegistratie zodanig gedetailleerd en uitgebouwd dat de daarvoor benodigde kwantitatieve gegevens omtrent de omvang en doorstroming der voorraden, die voordien vaak geheel los van de financiële administratie werden verzameld, daaraan kunnen worden ontleend. Aan de registratie van de voor de goederen uitgegeven resp. ontvangen geldbedragen wordt daartoe veelal een registratie in hoeveelheden toegevoegd en wel op zodanige wijze, dat beide registraties wederzijds in een systematisch controleverband tot elkaar staan. Voorzover vroeger alleen een registratie van kwantiteiten plaats vond, betekent de koppeling aan de financiële administratie niet alleen het verschaffen van een grotere zekerheid wat betreft de juistheid der kwantitatieve gegevens, doch ook het scheppen van een betere mogelijkheid tot het uitoefenen van controle op de verantwoording der financiële tegenprestaties. Aldus ontwikkelt de centrale administratie zich van een zuiver financiële boekhouding tot een meer algemeen georiënteerde bedrijfsadministratie, die ook op andere dan louter financiële aspecten van het bedrijfsgebeuren gericht is.

\section{Uitbreiding tot gedetailleerde, organisch gestructureerde produktiekosten administratie}

De wens komt op, de „kosten” (in de zin van historische kosten) niet alleen in hun samenhang met de uitgaven te kennen, doch ook in hun relatie tot de verschillende onderdelen van de organisatie en tot de vervaardigde produkten c.q. gepresteerde diensten. Naast de cijfers m.b.t. aankopen en uitgaven moeten daartoe cijfers m.b.t. de aanwending c.q. het verbruik der produktiemiddelen alsmede het gereedkomen der produkten worden verzameld.

Zo komt het tot een registratie van

m a b blz. 177 
- het verbruik van grondstoffen

- de tijdsbesteding van personeel

- de aanwending van duurzame produktiemiddelen

- het gereedkomen van de produktie.

Aanvankelijk geschiedt zulks op basis van z.g. historische kosten. Daarbij wordt het werkelijk verbruik resp. de werkelijke tijdsbesteding - ongeacht eventueel daarin begrepen verspilling - geboekt tegen de prijzen die bij de verkrijging van de betrokken goederen c.q. arbeidskracht in feite zijn betaald. Daardoor blijft nog steeds een sterke band met de kasadministratie bestaan. Daarnevens ontstaat echter een steeds sterker wordende gerichtheid op het interne bedrijfsgebeuren. Het handhaven van een gesloten rekeningverband vraagt in dit stadium nochtans geen andere maatregelen dan uitbreiding van het aantal gebruikte rekeningen en subrekeningen.

\section{Introductie van standaardkosten in de administratie}

Op grond van allerlei hier niet nader te bespreken theoretische zowel als praktische overwegingen, worden de in feite gedane uitgaven als uitgangspunt voor de voorcalculatorische kostprijsbepaling zowel als voor de nacalculatorische kostentoerekening, losgelaten. Naast de registratie der voor de verkrijging der produktiemiddelen gedane uitgaven komt er een registratie van de aanwending der produktiemiddelen op basis van standaard-prijzen en standaard-hoeveelheden. $\mathrm{Om}$ het verband tussen beide registraties en het evenwicht in de rekeningcijfers te handhaven, worden speciale rekeningen ingelast, waarop de voor de bedrijfsleiding zo belangrijke verschillen tussen beide tot uitdrukking worden gebracht (prijsverschillen, efficiencyverschillen en bezettingsverschillen).

De kostentoerekening wordt daardoor enerzijds bevrijd van de onjuiste identificatie van kosten met uitgaven, terwijl anderzijds, via de registratie van prijs-, efficiency- en bezettingsverschillen, het verband met de uitgaven blijft gehandhaafd, waardoor wordt voorkomen dat de kostencijfers gaan ,zweven”. Via analyseerbare verschillenrekeningen blijven zij ten nauwste verbonden met verifieerbare cijfers betreffende ontvangsten, uitgaven, bezittingen en schulden.

\section{Uitbreiding tot volledige budgetadministratie}

Met het begrip standaardkosten doen ramingen en budgetten, die voordien vrijwel uitsluitend in de administratie van de overheid, verenigingen e.d. een rol van betekenis speelden, hun intrede in de administratie van commerciële bedrijven. De wenselijkheid van een systematische confrontatie van de ramingen en budgetten met de werkelijkheid doet er velen zelfs toe besluiten ook de ramingen en budgetten in het systematisch geheel van de boekhouding op te nemen. Ook bij het nemen van die stap blijft de binding van de desbetreffende cijfers met de oorspronkelijke financiële boekhouding, waarin al het bedrijfsgebeuren wordt voorgesteld als een reeks van mutaties in kapitaal- of vermogenscomponenten, gehandhaafd.

\section{6a. Nevenontwikkeling buiten bet evenwichtsverband}

Naast de in het voorafgaande genoemde ontwikkeling die zich in belangrijke mate afspeelt binnen het kader van een rekeningstelsel met evenwichtsverband, heeft zich reeds van ouds een andere ontwikkeling afgetekend, nl. het ontstaan van allerlei registraties en informatieverwerkingen die niet of bezwaarlijk in dit min $\mathrm{m}$ a b blz. 178 
of meer formele verband kunnen worden ondergebracht. Het gaat daarbij in hoofdzaak om gegevens die van belang zijn voor de voorbereiding van beslissingen of ter verzekering van een goede en tijdige uitvoering van gecontracteerde prestaties en voorgenomen werkzaamheden. Het zou te ver voeren daarvan een uitputtende opsomming te geven. Wij volstaan daarom met het noemen van:

- inkoopdocumentatie (gegevens betreffende inkoopmogelijkheden en inkoopervaringen);

- administratie van lopende bestellingen (inkopen zowel als verkopen);

- agenda's (o.m. te verrichten betalingen per vervaldag);

- calculaties.

Hoewel er in het algemeen geen dwingende redenen zijn om dergelijke registraties en informatieverwerkingen in nauwe samenhang met de in de punten $1 \mathrm{t} / \mathrm{m} 6$ genoemde onderdelen van de administratie te verrichten, kan toch in tal van bedrijven worden waargenomen dat zij geheel of gedeeltelijk worden opgedragen aan functionarissen die belast zijn met de verzorging van het in gesloten rekeningverband gevoerde deel van de administratie. Zulks in hoofdzaak op grond van de geschiktheid die deze functionarissen normaliter voor dit werk hebben. Ook echter voor zover dit werk niet door dezelfde personen wordt verricht, leidt de systematische bestudering van de problematiek van de administratieve organisatie, zowel als studie van de ontwikkeling van de administratieve techniek tot het inzicht, dat deze werkzaamheden niet alleen een grote innerlijke samenhang ${ }^{1}$ ) doch ook een sterke technische verwantschap met de eerder genoemde onderdelen van de administratie vertonen, zodat het in het algemeen gewenst moet worden geacht deze werkzaamheden bij het ontwerpen van de administratieve organisatie mede in de beschouwingen te betrekken. Zoals wij straks zullen zien is die wenselijkheid nog toegenomen door de ontwikkelingen die de administratieve techniek de laatste jaren heeft doorgemaakt.

\section{Incorporatie van statistische rubriceringen}

Een van de eerste gevolgen van de invoering van technische hulpmiddelen in de administratie was het wegvallen van de voordien veelal bestaande kloof tussen boekhoudkundige en statistische rubriceringen. Reeds de toepassing van losbladige boeken en kaartsystemen en in aansluiting daarop het gebruik van doorschrijfapparaturen en boekhoudmachines maakten een vrijwel onbeperkte uitbreiding van het aantal in de boekhouding onder te brengen rekeningen mogelijk. De toepassing van het ponskaartensysteem voor administratieve doeleinden heeft echter eerst recht de grens tussen boekhouding en statistiek doen vervagen, doordat dezelfde kaarten die dienst doen voor de specifiek comptabele registratie ook kunnen worden gebruikt voor het samenstellen van alle gewenste analyses en hergroeperingen.

\section{Uitbreiding met registraties betreffende de reservering van produktiecapaciteit} met precisering naar tijdstip en daarop aansluitende voortgangscontrole

Doelmatige planning van produktiewerkzaamheden vraagt zowel een registratie van de beschikbare produktiecapaciteit en van het beslag dat daarop door ge-

1) De verschillende registraties hebben immers voor een groot deel betrekking op dezelfde of onderling samenhangende zaken.

m a b blz. 179 
plande werkzaamheden wordt gelegd, als een registratie van de voortgang welke met de uitvoering dier werkzaamheden wordt gemaakt.

Het verband van deze registraties met de in het voorafgaande besproken onderdelen van de administratie lijkt op het eerste gezicht nogal verwijderd. Dat verband wordt echter duidelijk wanneer men bedenkt dat dezelfde gegevens die bij de registratie van de planning worden vastgelegd ook weer een rol spelen bij het verstrekken van de werkopdrachten aan het uitvoerend personeel en bij de verantwoording van de verrichte werkzaamheden ten behoeve van de loonberekening en de registratie in loon- en kostprijs administratie. Hetzelfde geldt voor de reservering en de verantwoording van machine-uren en materialen. Een soortgelijk verband bestaat tussen de voortgangsmelding ten behoeve van de planning en de verantwoording van de gereedgekomen produkten ten behoeve van de resultatenbepaling. In het verleden zijn die verbanden niet altijd even duidelijk onderkend, zulks niet alleen tot schade van de administratieve efficiency (veelschrijverij) doch ook tot schade van de betrouwbaarheid der verschillende aan de bedrijfsleiding voorgelegde overzichten. $Z$ ijn deze overzichten namelijk niet uit dezelfde basisgegevens opgebouwd en worden de onderlinge controlemogelijkheden niet onderkend, dan zullen allerlei storende afwijkingen in deze overzichten kunnen optreden. In de loop der laatste decennia is daarin bij tal van bedrijven door een bredere aanpak van het gehele complex van samenhangende registraties reeds veel verbetering gekomen.

(Dat bij de planning en de voortgangscontrole in den regel een andere voorstellingswijze wordt gebruikt dan die welke in de overige administratie wordt gebezigd, is niet van principiële betekenis. Bij toepassing van elektronische adminitratiemachines komt het verschil zelfs geheel te vervallen.)

\section{Uitbreiding van het administratieplan tot bet gebele stelsel van interne en externe communicatie door middel van informatiedragers (o.a. formulieren)}

Reeds vroeg werd b.v. de facturering als een onderdeel van de administratie beschouwd; vooral het verband met de financiële verantwoording der opbrengsten gaf daartoe aanleiding. Met het voortschrijden van de bestudering van de problematiek der administratieve organisatie en de efficiency der administratieve procedures wint echter het inzicht veld, dat het t.a.v. de verkopen zinvol is niet alleen de facturering doch de gehele interne en externe communicatie m.b.t. de orderbehandeling te betrekken in het ontwerp van de administratieve organisatie en de administratieve procedures; daarbij moeten immers voor een groot deel dezelfde gegevens worden gehanteerd, zodat door toepassing van daartoe geëigende technieken veel duplicering van arbeid kan worden vermeden (b.v. door toepassing van doorschrijfmethoden of machine-activerende informatiedragers).

Zo zal ook bij het voorbereiden, in gang zetten, coördineren en verantwoorden van produktiewerkzaamheden in den regel een grote samenhang bestaan tussen de gegevens die moeten voorkomen op:

- planningsdocumenten

- werkopdrachten

- materiaalaanwijzingen

- gereedschapsuitgifte stukken

- verantwoordingsstukken betr. tijd en materiaalverbruik

- transportopdrachten 
- stukken ten behoeve van de voortgangsmelding

- stukken ten behoeve van de kwaliteitscontrole.

Hetzelfde geldt voor allerlei andere communicatiestukken die de voorbereiding, uitvoering, controle en verantwoording van bedrijfsactiviteiten begeleiden.

Tot dit punt was de ontwikkeling van de administratieve activiteiten en van de inzichten in wat als een doelmatige afgrenzing van de onderling samenhangende problematiek moet worden beschouwd, gevorderd, toen de komst van elektronische administratiemachines tot een nieuwe bezinning noopte. Deze bezinning heeft een tiende, elfde en twaalfde ontwikkelingsfase ingeleid.

\section{Uitbreiding van de administratieve bemoeienis tot het toepassen van vaste} beslissingsregels t.a.v. routinebeslissingen m.b.t. de bedrijfsvoering

Voor zover beslissingen kunnen worden genomen op grond van

(a) concrete gegevens omtrent oude en nieuwe feiten en/of bestaande of verwachte toestanden en verhoudingen;

(b) eenduidig geformuleerde beslissingsregels

hetgeen b.v. het geval kan zijn m.b.t. het accepteren van orders, het aanvullen van voorraden e.d., kan het nemen van die beslissingen ${ }^{2}$ ) worden overgedragen aan een machine. Daar de onder (a) bedoelde gegevens veelal zullen kunnen worden ontleend aan de in de vorige punten genoemde onderdelen van de administratie en het nemen van beslissingen volgens de onder (b) bedoelde regels kan worden uitgevoerd door dezelfde machines als die welke ook het bijhouden van vorenbedoelde onderdelen van de administratie kunnen verzorgen, ligt het voor de hand ook deze beslissingsprocessen in de administratieve problematiek te betrekken en te onderzoeken in hoeverre de uitvoering dier processen op doelmatige wijze met de verzorging der eerder genoemde onderdelen van de administratie kan worden geïntegreerd.

Daar het nemen van de hierbedoelde beslissingen technisch volkomen vergelijkbaar is met de uitvoering van andere informatieverwerkingsprocessen, terwijl de betrokken basisinformatie vaak reeds onderdeel van de administratie uitmaakt en ook de strekking van de desbetreffende informatieverwerking (cijfers laten spreken) volkomen aansluit op die van andere administratieve processen, is het alleszins verantwoord dit soort beslissingsprocessen - ook daar waar nog geen sprake is van toepassing van elektronische apparatuur - begripmatig tot de administratie te rekenen.

(N.B. Wellicht ten overvloede zij er op gewezen, dat het hier alleen gaat om beslissingsprocessen die aan de eerder genoemde voorwaarden voldoen. Beslissingen die geheel of gedeeltelijk gebaseerd zijn op een min of meer gevoelsmatige afweging van imponderabele factoren of op de hantering van niet exact formuleerbare criteria, vallen daar dus buiten. Het allerwege waarneembare streven naar meer wetenschappelijk gefundeerde bedrijfsvoering doet het gebied van laatstbedoelde beslissingen, die door sommigen als echte beslissingen worden gekwalificeerd, steeds kleiner worden, hetgeen natuurlijk niet wegneemt dat die beslissingen in den regel tot de meest belangrijke zullen behoren; zij zullen echter, in tegenstelling tot de overige die wij in zekere zin als formele beslissingen zouden kunnen

\footnotetext{
2) Voor de motivering van het gebruik van deze term zij verwezen naar de noot aan het slot van het vorig artikel.
} 
kwalificeren, doch die eigenlijk meer het karakter van volkomen gedetermineerde conclusies hebben, gewoonlijk betrekkelijk gering in aantal zijn.)

\section{Uitbreiding van het administratieproces tot toetsing van rekeningcijfers aan beoordelingsnormen en rapportering volgens de uitzonderingsregel}

De omvang van het cijfermateriaal dat ter beschikking van de leiding kan worden gesteld voor beleidsbepaling, toezicht en controle is door de toepassing van moderne administratiemethoden en snelle verwerkingsapparaturen zodanig toegenomen, dat dit in tal van bedrijven een ernstig probleem is gaan vormen voor hen die van die gegevens moeten kennisnemen.

Meer en meer is men daarom tot de overtuiging gekomen, dat de rapportering dient te geschieden volgens het z.g. uitzonderingsbeginsel (management by exception). Daarbij worden alleen die gegevens voorgelegd waarmee iets bijzonders aan de hand is in dien zin dat er een relevante afwijking is van de daarvoor gestelde normen. De beschikbare gegevens moeten daartoe een kritische voorbewerking ondergaan. Vooral sinds het verschijnen van elektronische administratiemachines is aan de toepassing van dit beginsel bijzondere aandacht geschonken. Het is daarbij nl. mogelijk de bedoelde voorbewerking zodanig in het administratieproces te incorporeren dat de rapportering automatisch beperkt blijft tot datgene wat werkelijk voor de leiding van belang is. Het spreekt vanzelf dat deze gedachte gemakkelijker en consequenter kan worden doorgevoerd naarmate er ten behoeve van de beleidsbepaling meer met begrotingen, voorcalculaties en normcijfers wordt gewerkt, iets waaraan in het kader van het streven naar een doelmatige organisatie ook uit anderen hoofde steeds meer aandacht wordt geschonken. Dezelfde gedachte kan uiteraard ook worden toegepast door de hantering der voorbewerkingsregels op te dragen aan mensen, zodat ook hier de afgrenzing van het begrip administratie niet afhankelijk behoeft te worden gesteld van de gebruikte apparatuur.

\section{Rechtstreekse communicatie met operationele functionarissen en produktie- machines}

De rechtstreekse communicatie van administratiemachines met operationele functionarissen en produktiemachines kan wellicht als de laatste maar nog nauwelijks begonnen fase van het administratieve ontwikkelingsproces worden beschouwd. Daarbij kan verkeer in twee richtingen worden onderscheiden:

- het doorgeven van door de administratiemachine geproduceerde gegevens en beslissingen aan de operationele functionarissen (inkopers, verkopers, fabricagechefs e.d.) dan wel - in de vorm van besturingsimpulsen - aan de produktiemachines;

- het doorgeven van vragen en mededelingen uitgaande van bedoelde functionarissen resp. het overbrengen van allerlei berichten uitgaand van de produktiemachines aan de administratie-apparatuur.

Het voltrekken van deze fase betekent in feite het opheffen van de scheiding tussen de administratie en de eigenlijke bedrijfsuitoefening. Het zal weinig betoog behoeven dat een dergelijke stap vergaande consequenties heeft o.m. met betrekking tot de interne controle. Voorshands zullen wij ons echter, naar zich laat aanzien, niet op grote schaal met de daaraan verbonden problematiek behoeven bezig te houden, daar de toepassing van de annezige technische mogelijkheden op dit 
gebied voorlopig nog wel tot enkele speciale bedrijven en bedrijfsonderdelen beperkt zal blijven.

Samenvattende karakteristiek van bet in dit artikel besproken deel van de administratie

In aansluiting op de in het vorige artikel besproken nieuwe definitie van administreren, welke alle genoemde fasen omvat, kan de volgende samenvattende opsomming van doeleinden van het tot sector $A$ behorende deel van de administratie worden gegeven:

1. Het verschaffen van geanalyseerde en samenvattende informatie omtrent bedrijfsactiviteiten, vermogenrechtelijke verhoudingen e.d. zowel ten behoeve van de algemene beleidsbepaling en beleidsbeoordeling als ten behoeve van de beheersing der onderscheiden activiteiten (gegevens betreffende kostprijzen, omzetten, resultaten, financiering, liquiditeit, efficiency, rentabiliteit, begrotingen enz.).

2. Het verschaffen van detailinformatie betreffende personen, objecten, overeenkomsten e.d. ten behoeve van het voorbereiden van beslissingen alsmede het sluiten en uitvoeren van overeenkomsten (bijv.: personeeldocumentatie, inkoopdocumentatie, grondtijden documentatie, gegevens betr. de vrije capaciteit der verschillende produktiemiddelen).

3. Het verwerken van informatie ten behoeve van de uitvoering van voorschriften, regelingen, overeenkomsten e.d. (het nemen van formele beslissingen).

4. Het vastleggen van te verrichten werkzaamheden (ordervastlegging, capaciteitsreservering, agendering).

5. Het verzorgen van een deel van de communicatie met interne bedrijfsfunctionarissen (event. produktiemachines) en derden (bijv.: opdrachtverstrekking, werkvoorbereiding, werkindeling, verzorging van de coördinatie van afgesplitste werkzaamheden, verzorging van voortgangsmelding, loonaf rekening, facturering).

6. Het afleggen van rekening en verantwoording en het uitoefenen van controle (samenstellen van overzichten ter beoordeling van het gevoerde beheer, verantwoording door de leiding aan eigenaren of derden, verantwoording door subalterne functionarissen aan de leiding op haar verschillende niveaus, nacalculaties, resultatenoverzichten, verantwoording van en controle op bewaarders van waarden, kwijting bij overdracht van waarden).

7. Het voldoen aan wettelijke, statutaire en contractuele verplichtingen tot het overleggen of publiceren van bepaalde gegevens.

\section{Conclusies}

In een volgend artikel zullen wij nagaan welke conclusies uit de in het vorige artikel gegeven beschouwingen omtrent het begrip ,,administratie" en het in dit artikel gegeven overzicht van de ontwikkeling op het gebied van de praktische toepassing kunnen worden getrokken. Zulks in het bijzonder wat betreft de relatie tussen administratie en organisatie. Zo ook wat betreft de organisatorische plaats van de administratie, de administrateurs en de administratieve deskundigen. Tevens zal dan worden nagegaan wat daaruit voortvloeit t.a.v. het beheer van centrale informatieverwerkingsapparaturen en de daarbij behorende informatieverzamelingen. Tenslotte zullen nog de consekwenties onder ogen worden gezien welke de geschetste ontwikkeling voor de praktiserende accountant heeft. 


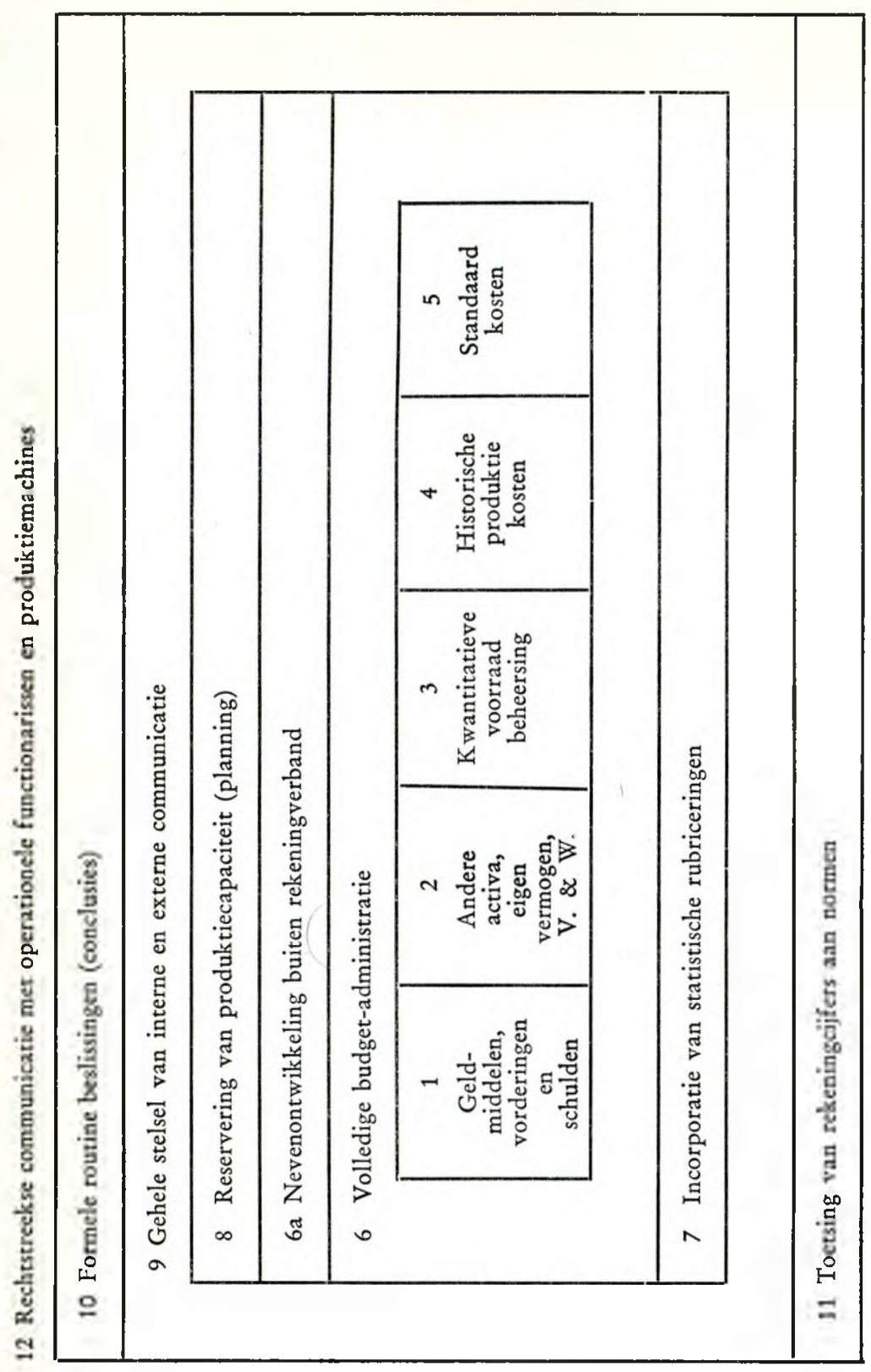

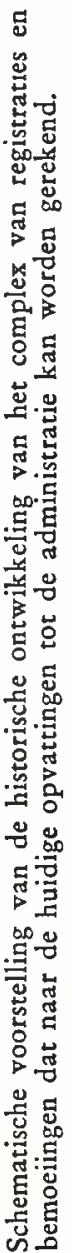

